\title{
A conversation with Doug Lowy and John Schiller
}

$T_{\text {the }}$ he combined efforts of Doug Lowy and John Schiller form the basis of the biology behind the vaccines for HPV (human papillomavirus), which underlies cervical cancers as well as oropharyngeal cancers. With widespread uptake, these vaccines have the potential to wipe out these cancers in a generation. The JCI spoke with Schiller and Lowy (Figure 1) from the National Cancer Institute when they were in New York City to collect the 2017 Lasker DeBakey Clinical Medical Research Award. Watch the full interview at www.jci.org/videos/cgms to find out more about HPV biology, how exciting it was to hear the early results of the vaccine trial, and whether they have ever fought with each other.

JCI: Where did you grow up?

Schiller: I grew up in Madison, Wisconsin, and was quite a rambunctious kid. I was very active, but also read a lot. My parents weren't particularly academic. My father had a small business where he sold John Deere tractors, and my mom was a homemaker. We had a lot of emphasis on education, but I didn't have role models in terms of getting into science. Initially, I thought I wanted to be a park ranger because I liked the idea of natural history and being out in the woods. But I got to realize that really, what park rangers do is deal with unruly tourists.

I was always interested in science; I studied all the plants and animals that were in the area and could identify them. I always had a very scientific bent, ever since I was little, but I was one of these people who never wanted to commit. I didn't have an academic major until my junior year of college, but I took all the prerequisites for molecular biology, from the physics to the math. I eventually knew I wanted to be a researcher and decided to get a PhD. I went into microbiology because that's where the best molecular biology was being done $-E$. coli and their phages (bacterial viruses) were where some of the most interesting molecular biology was being done.

Lowy: I was born in the Bronx in New York City and grew up there and stayed in the Bronx, more or less, through high school. My parents were both general practitioners, working in the Bronx. I thought from a very early age that I would follow in their footsteps. Being in research is something that I did not envision and didn't seriously think about until I was in medical school and beyond.

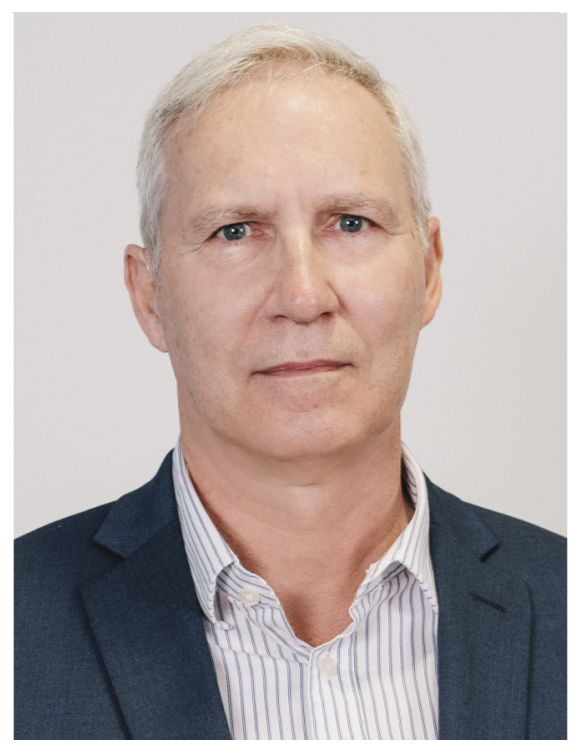

Figure 1. John Schiller and Doug Lowy on September 14, 2017, in New York City. Image credit: Alexey Levchenko.

I was a good student, but I was very interested in sports, electric trains, building model cars, and things like that. I had very little interest in science, more interest in disease and health, as my parents would tell me about things like the relationship between cigarette smoking and cancer because that was being identified when I was growing up.

I actually think of myself much more as being a follower rather than a trailblazer. I followed in my brother's footsteps when I went to college. I followed in my mother's footsteps when I went to medical school - I really think of myself as imitating people that I respect rather than striking out on my own.

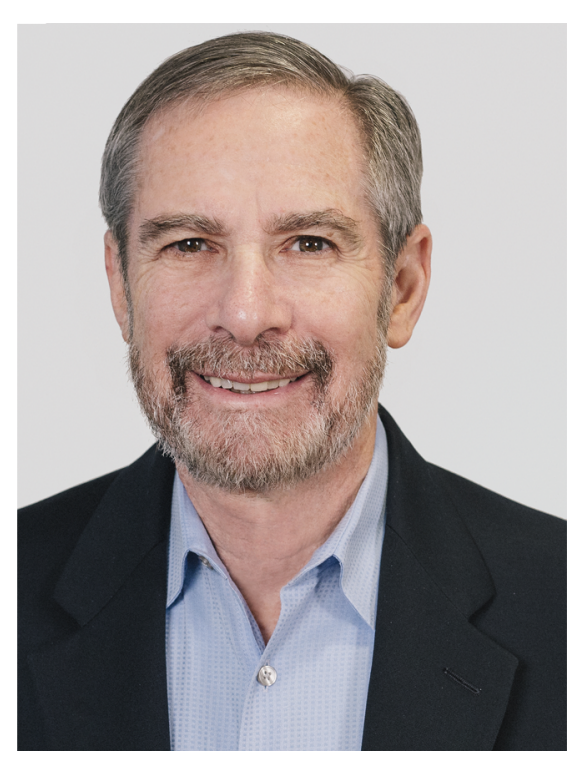

I became very interested in infectious diseases as a result of taking microbiology when I was a medical student. I was particularly intrigued by the positive symbiotic relationship between microorganisms and the host. I had always thought about microbes as being universally harmful rather than potentially beneficial. And the balance between being inoffensive or neutral, being bene- 
ates, if they were male, basically had to do some kind of uniform service activity. Most people ended up going to Vietnam. But you could, if you were selected, go to the NIH for research training, and that's what I ended up doing.

Initially, I worked on retroviruses, which is what my training was when I was first at NIH in the Institute of Allergy and Infectious Diseases. And then my research went into the retroviruses that had oncogenes - acute transforming retroviruses. My interests went on to papillomaviruses as another version of viruses that could cause cell transformation, but that class of viruses was much less studied than the retroviruses were.

JCI: So John, how did you decide to do your postdoc with Doug?

Schiller: I was starting to do some strategic thinking about science. My PhD, which was in diphtheria biology, was quite mediocre. I was actually a little bit disenchanted with bacterial pathogenesis because it seemed very balkanized. Everybody was studying their little bug; there were no overriding common elements that were interesting. This was the time that tumor virology was coming up, and I thought it would be really cool to study. But my PhD wasn't strong enough, I didn't think, to apply to the really super top labs. I went to the Fred Hutchinson where they had a very strong tumor virology group, and I asked the faculty, Who's up-and-coming in the field and a really good person? At the top of everybody's list was Doug.

I applied to his laboratory to work on retroviruses, but he said, "What you're propose is a nice thing, but I'm just starting to work on papillomaviruses." My reaction was, Papillomaviruses? What? I read a little bit about the limited knowledge, thought, Wow! This is really a time to get into papillomaviruses. I wrote back with a project related to papillomaviruses, which we actually ended up doing.

JCI: Doug, I take it he didn't sell himself as doing a mediocre $\mathrm{PhD}$ when he applied?

Lowy: He wrote a terrific proposal, and I was very impressed. John clearly saw the potential for studying papillomaviruses. Essentially, nothing was known about their molecular and genetic organization. We spent a fair amount of time using a model system, the bovine papillomavirus (BPV), to work out the molecular genetics.

JCI: John, you've before told the story of your first aha moment - the seminar you attended at the NIH from Harald zur Hausen - talking about HPV underlying cervical cancer. Did you come back to Doug and say, No more BPV; we're studying HPV!

Schiller: No. What we were studying on BPV was also significant. But we started to transition to HPV because we realized that there were important differences between the way BPV transforms cells and the way HPVs do. For instance, we looked to see whether BPV interacted with p53, and we couldn't find any interaction. But for HPV, that's one of its primary activities: it induces degradation of $\mathrm{p} 53$, a critical tumor suppressor. As we started to realize that all the different papillomavirus weren't doing it the same way, we transitioned more into studying HPVs.

JCI: At what point did you start thinking about a vaccine?

Lowy: In the early '90s. We had been convinced from the molecular biology that HPV was important for cervical cancer. We were thinking about the structural proteins of the virus instead of the genes and the proteins that regulate the virus. And quite by accident, the first experiments that we ended up doing were experiments that were able to test whether expressing the major protein of the papillomavirus would self-assemble and form virus-like particles (VLPs). Another thing is that Reinhard Kirnbauer, who was the dermatologist postdoctoral fellow in the lab, was willing to do this high-risk research. We were very fortunate that he was able to make VLPs in the very first set of experiments where he expressed BPV L1 [one of the two outer viral capsid proteins]. At that point, it was a question of asking, Well, might this be a vaccine?

JCI: You were puzzling over how to get the HPV L1 capsid protein to form VLP at what point did you have the revelation that the HPV16 strain you were using had a mutation that was causing it not to selfassemble correctly?

Schiller: We were really disappointed because when Reinhard tried again to express HPV L1 in insect cells, with the exact same vectors from HPV16, we could barely find any particles at all. About the same time, we started to make VLP from a rhesus monkey papillomavirus. We wanted to show we could induce high titers of antibodies that block infection in a nonhuman primate. This rhesus papillomavirus turns out to actually be very closely related to HPV16. When we tried to make the VLPs of that strain, it worked just as well as with BPV. We thought that it wasn't that there were two classes, one that did assemble and one that didn't; the reason why we were not successful was maybe because BPV is a cutaneous virus. It replicates in the normal type of skin on the cow, and HPV is more mucosal. We thought maybe there was a difference between these two classes. But rhesus papillomaviruses cause cervical cancer in monkeys. That's when we really thought the most likely possibility was that HPV16, which had been used in most of the labs around the world, that Harald zur Hausen had originally isolated, was a mutant, because it was isolated from a cancer. And cancers are notoriously genetically unstable.

JCI: Once you got the VLPs to assemble properly using a nonmutant HPV strain, you had some promising data that led you to start a pilot human clinical trial with the NCI at Hopkins in a small group, and it was amazingly successful. Do you think that the unique nature of the NIH was what allowed you to get to that point in the beginning?

Lowy: The freedom of the intramural program at the NIH was critically important in large part because we had never worked in this area before. We had studied the genes that were responsible for transformation or regulating gene expression, but we had never studied the structure, had no background in immunology or in vaccinology. One of the big advantages of the intramural program is that you have leveled resources.

In retrospect, we were fortunate that, because we had worked on BPV, we were able to show not only that we could get self-assembly of particles, but because we had developed a neutralization assay in vitro, we could also show very high levels of neutralizing antibodies, much higher than with most other vaccine types. And that gave us the positive con- 
trol to then be encouraged to go forward with the human papillomavirus studies. Other people who were working in this area tended to focus on HPV first, for which there either was no neutralization assay or a very cumbersome one.

JCI: How many cervical cancer cases are there per year, and how did your idea get carried forward to larger trials?

Schiller: There's about half a million worldwide and about 250,000 deaths. From the point of view of the pharmaceutical industries, I think their biggest issue was that the track record for sexually transmitted disease vaccines at that point was miserable. People had tried to do herpes virus vaccines that seemed to work in animals, and they didn't work in people, same for chlamydia. People had been working on HIV vaccines, and none of them seemed very promising. The biggest intellectual hurdle was that HPV isn't like a flu vaccine where you may be exposed once or twice. If you have a sexual partner, you may be getting exposed repeatedly over a course of years because these viruses tend to persist.

It was really a leap of faith for Merck and GSK to spend hundreds of millions of dollars to test our vaccine and see whether they would work. Merck did an HIV vaccine trial during the time the HPV vaccine was working great. With the HIV vaccine, they spent hundreds of millions of dollars and they got nothing out of it, other than knowing that their particular vaccine doesn't work in people.

JCI: You had seen some initial positive data, but did you know that it was going to be as successful as it was?

Lowy: Certainly not immediately. For us, finding out about the results of the monovalent HVP16 trial that Merck conducted - published in 2002 but it was first announced in 2001 at a papillomavirus meeting - was simply astounding because there were 41 cases of HPV16 infection in that clinical trial. All 41 cases were in the placebo group and zero in the HPV16 group. For us, this clearly indicated this was going to work and be highly effective because you just don't get results like that ordinarily in a clinical trial.

JCI: Did you have some champagne when you found out?

Schiller: Actually, we weren't together. It was at the International Papillomavirus Meeting in Brazil, which is usually held every year-and-a-half. I was actually the moderator of that particular session. What's interesting is that the person who reported it, Laura Koutsky from the University of Washington, who was a lead epidemiologist on the study, didn't tell anybody that she was going to talk about it. We were all sort of dumbfounded when she was finished. I remember afterwards saying, "Ladies and gentlemen, you've just seen history."

JCI: Okay, I'll change my question: Did you have a caipirinha?

Schiller: I had a caipirinha afterwards. I do remember that, absolutely.

JCI: Doug, you have been deputy director of the NCI since the ' 90 s and, for the last 2.5 years, the acting director of the NCI. What made you take on more administrative roles?

Lowy: I have gotten a tremendous amount from being in the intramural program at NCI and wanted to see whether I might be able to do more as a way of giving back. In the '90s, I started out as deputy director of the intramural NCI program. In 2010, when Harold Varmus became the NCI director, he asked if I would become the deputy NCI director. But before I said yes or no, I turned to John and said, "Should I do this?" And he said yes. I asked the person who was the director of the intramural program, and he thought I should. And then, I asked the most important person, and my wife said
I should too. So I ended up doing it. Then, when Harold left, I became the acting director, and it has been very interesting.

Part of what I love about doing research is being able to address important questions. Many of them are basic; some have translational and clinical implications. But being involved at the policy level gives you an opportunity to do more, although not as directly. You can help researchers with development of their careers. You can try to put more emphasis in one area of research as opposed to another. There are so many different ways in which you can try to help the cancer research enterprise. A very important part of it for me has been to strongly support investigator-initiated research because to me, that is very important for leading to the clinically important interventions of tomorrow.

Schiller: Doug is a more outstanding scientist and, at the same time, better administrator than anybody I've ever met. He can juggle more balls in the air at the same time than anybody and do a really great job for all of them.

JCI: If you could not have been a doctor or a scientist, what do you think you would have done in your lives? What would have kept you engaged?

Lowy: If I had the talent, my first two choices would either to have been a wonderful miler or 1,500-meter runner. Second choice would have been to play football in the NFL. But when you're talking about what might have been feasible, I would have really liked to have been a high school biology teacher.

Schiller: Maybe a professional trout fly fisherman. I was always really an academic, and that is the perfect thing for me. So if I couldn't do science in an academic setting, I probably would have been a historian studying the flow of ideas in cultures, particularly when distinct cultures interact.

\section{Ushma S. Neill}

